\title{
Deep-Sea Cobalt Crusts Water Jet Cutting Ability
}

\author{
Zhonghua Huang ${ }^{1}$, Ya Xie ${ }^{2}$ \\ ${ }^{1}$ College of Mechanical Engineering, Hunan Institute of Engineering, Xiangtan, China \\ ${ }^{2}$ College of Computer and Communication, Hunan Institute of Engineering, Xiangtan, China \\ E-mail:csu707@163.com
}

Received April 19, 2011; revised May 29, 2011; accepted June 20, 2011

\begin{abstract}
Deep-sea cobalt crusts water jet cutting method is proposed to avoid cutter impact load. With simulation calculations and experimental tests, water jet system parameters and its cutting ability were studied. Simulation results show that working pressure, ejection range and ejection angle of water jet system are main parameters of its cutting ability. Its important degree is in turn the working pressure, ejection range and ejection angle. Increasing water jet system working pressure is the most effective way to improve its cutting ability. When water jet working pressure is constant, in order to improve its cutting ability, the ejection range should be less than $4 \mathrm{~mm}$ (four times of nozzle diameter) and the ejection angle should be about $13^{\circ}$. Experimental results show that there is a threshold pressure during water jet cutting cobalt crusts simulation material. With the increase of water jet working pressure, its cutting ability increases dramatically. With the increasing of water jet ejection range, its cutting ability decreases sharply. The optimal ejection angle is about $13^{\circ}$.
\end{abstract}

Keywords: Water Jet, System Parameters, Deep-Sea Cobalt Crusts, Cutting Ability

\section{Introduction}

As land mineral resources are being exhausted, many countries are paying attention to deep-sea resources development and utilization. Deep-sea cobalt crusts are metal minerals, which is located in sea mountain [1]. Deep-sea cobalt crusts are rich in rare metals Co and Pt. It is widely considered as one of the most attractive ocean floor mineral resources. Considering economic value and strategic significance of deep-sea cobalt crusts resources, exploitation techniques of cobalt crusts resources are studied widely. One research direction is about cobalt crusts resources cutting method [2-4]. Spiral drum cut teeth cutting is seen as an effective cobalt crusts cutting method. In order to improve cutting efficiency, cobalt crusts vibration cutting method is proposed in reference [5], an eccentric mechanism is amounted in spiral drum. When spiral drum rotates, an additional vibration cutting force is generated and the cutting efficiency is increased.

In a real deep-sea cobalt crusts mining system, high cutting efficiency is important, but safety of mining system is more important. Impact load and vibration of spiral drum are inevitable when cutter cutting deep-sea cobalt crusts. Excessive impact load may lead to the dumping of mining vehicle is proposed in reference [6]. Deep-

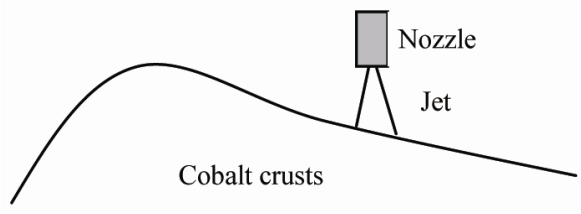

Figure 1. The schematic of water jet cutting cobalt crusts.

sea cobalt crusts water jet cutting method is proposed in this paper to decrease impact load of cutter.

\section{Water Jet Cutting Method}

In order to improve the safety of mining system, high pressure water jet is used to cutting cobalt crusts. The schematic of water jet cutting deep-sea cobalt is shown in Figure 1, nozzle is used to generate high pressure water jet. Hitting power is generated on the surface of cobalt crusts when high speed jet impacts with cobalt crusts. Compressive stress and shear stress are generated in the inner of cobalt crusts when hitting power is working on cobalt crusts. Initial crack is formed when compressive stress is greater than compressive strength or shear stress is greater than shear strength. After the forming of initial crack, water jet is infiltrated into the crack and the cutting speed is accelerated. The reaction force created by 


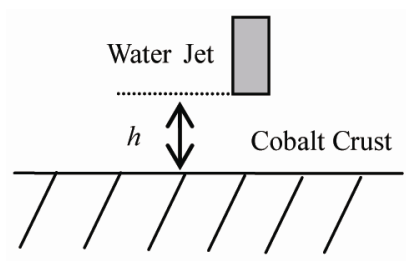

Figure 2. Water jet cutting simulation model vs ejection range.

water jet is minor. So water jet cutting cobalt crusts can avoid impact load more effectively compared with cutter cutting cobalt crust alone.

From the work principle of water jet cutting cobalt crusts, it shows that working pressure, ejection range and ejection angle are three key parameters of water jet cutting system. Theoretically, jet cutting ability is proportional to the working pressure. The working pressure of an actual water jet system is always restricted to equipment costs and the maximum output pressure of pressure booster. So the working pressure of water jet system doesn't need very high considering the system cost. Experimental tests show that water jet working pressure must be greater than cobalt crusts compressive strength in order to realize effective cobalt crusts cutting. As for the cutting of cobalt crusts simulation materials, water jet system working pressure of 5 - 10MPa is suitable [6].

In order to study the relationship between water jet system parameters and its cutting ability, simulation calculations and experimental tests are carried out.

\section{Simulation Research}

Simulation calculation is carried out to obtain the relationship between water jet system parameters and its cutting ability. At first, the relationship between ejection range and its cutting ability is simulated. The simulation model is shown in Figure 2, the working pressure of water jet is constant, $h$ is distance between water jet and cobalt crusts, ejection range variation is simulated with $h$ variation. The simulation software is FLUENT [7]. Simulation parameters are as follows: water jet inlet velocity is $100 \mathrm{~m} / \mathrm{s}$, nozzle diameter is $1 \mathrm{~mm}$, ejection range is $1 \mathrm{~mm}-11 \mathrm{~mm}$ 。

Figure 3 is water jet velocity simulation results when ejection range is $3 \mathrm{~mm}$, which shows that water jet collide cobalt crusts surface after perpendicular incoming and water jet velocity direction changes from vertical direction into horizontal direction. Water jet generates water pressure on cobalt crusts surface, shear stress and hitting power.

Water jet cutting ability is decided by maximum water pressure, maximum shear stress and maximum hitting power. Figures 4-6 are simulation curves of maximum

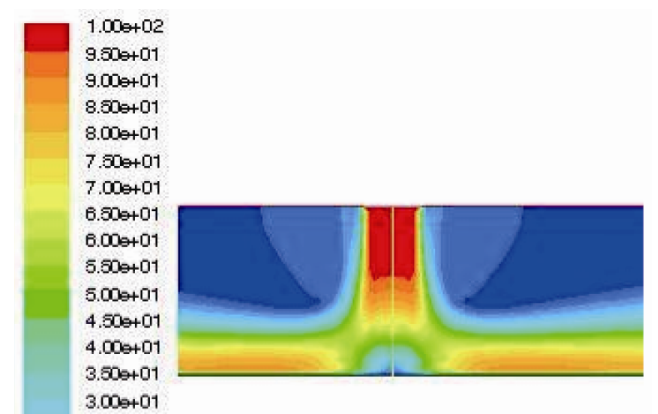

Figure 3. Water jet velocity simulation results $(\mathrm{h}=\mathbf{3} \mathbf{~ m m})$.

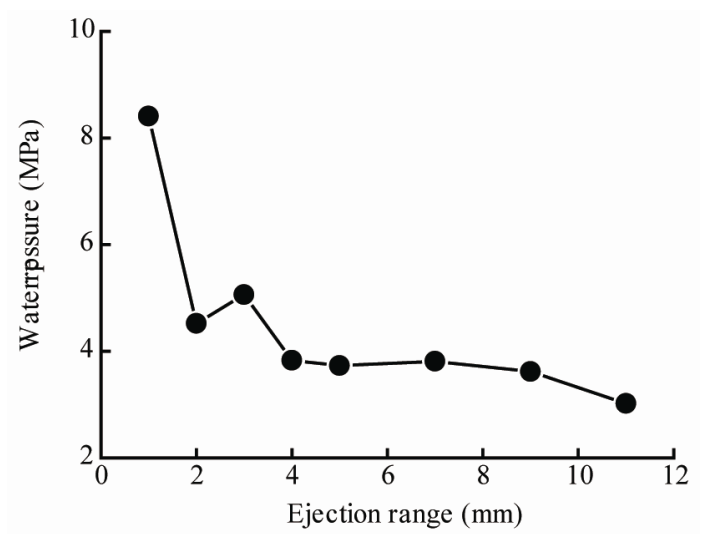

Figure 4. Maximum water pressure vs ejection range.

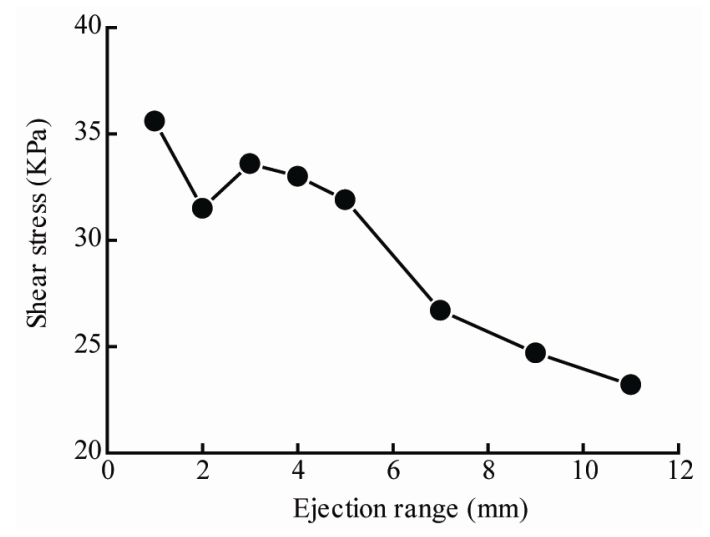

Figure 5. Maximum shear stress vs ejection range.

water pressure, maximum shear stress and maximum water jet hitting power while water jet cutting cobalt crusts under different ejection range. It can be seen from Figure 4 that with the increasing of ejection range, maximum water pressure is decreased sharply when ejection range changes from $1 \mathrm{~mm}$ to $4 \mathrm{~mm}$. When ejection range is greater than $4 \mathrm{~mm}$, the maximum water pressure is almost in steady status. It can be seen from Figure 5 that maximum shear stress is decreased with ejection range increasing. When ejection range is increased from $1 \mathrm{~mm}$ - $5 \mathrm{~mm}$, maximum shear stress ran- 


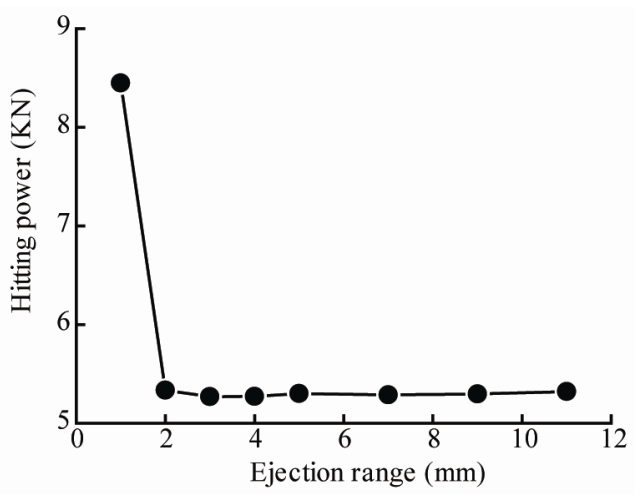

Figure 6. Maximum hitting power vs ejection range.

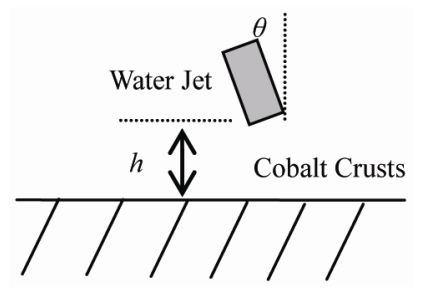

Figure 7. Simulation model vs ejection angle.

geability is small. When ejection range is greater than 5 $\mathrm{mm}$, maximum shear stress decreasing velocity is accelerated. It can be seen from Figure 6 that with the increasing of ejection range, maximum water jet hitting power is decreased sharply while ejection range is increased from $1 \mathrm{~mm}-2 \mathrm{~mm}$. When ejection range is greater than $3 \mathrm{~mm}$, the maximum hitting power is almost in steady status.

Simulation results show that ejection range is a key parameter to water jet cutting ability, with the increasing of ejection range, water jet cutting ability is decreased sharply, the optimal ejection range of water jet system is $1 \mathrm{~mm}-4 \mathrm{~mm}$ (four times of nozzle diameter).

At last, water jet ejection angle with its cutting ability is simulated. The simulation model is shown in Figure 7, the working pressure and ejection angle of water jet are constant, and ejection angle variation is simulated incidence angle $\theta$ variation. Simulation parameters are as follows: water jet inlet velocity is $100 \mathrm{~m} / \mathrm{s}$, ejection range $h=5 \mathrm{~mm}$, ejection angle $\theta$ is $0^{\circ}-30^{\circ}$.

Figure 8 is water jet velocity simulation results while ejection angle $\theta=13^{\circ}$, which shows that water jet collide cobalt crusts surface after oblique incoming and water jet velocity direction changes from vertical direction into horizontal direction. There is obvious velocity variance in horizontal water jet.

Figures 9-11 are simulation curves of maxi- mum water pressure, maximum shear stress and maxi- mum water jet hitting power while water jet cutting co- balt crusts under different ejection angle. It can be seen from
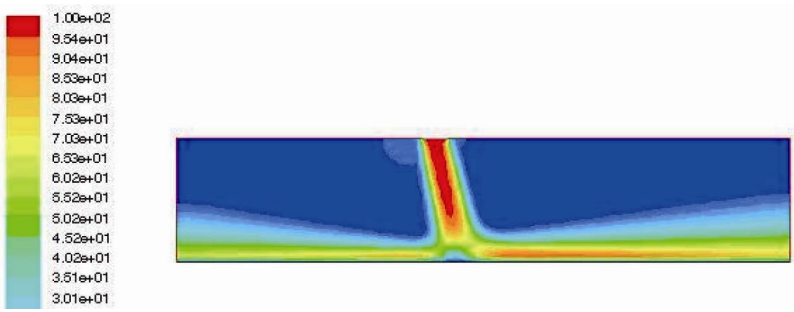

Figure 8. Water jet velocity simulation results $\left(\theta=13^{\circ}\right)$.

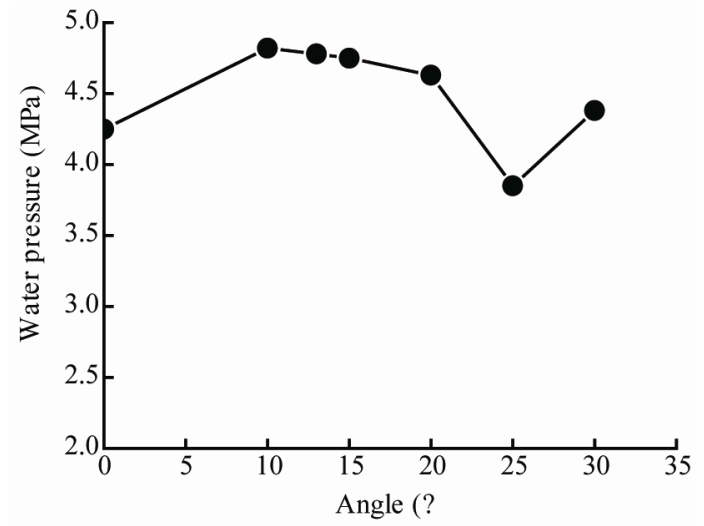

Figure 9. Maximum water pressure vs ejection angle.

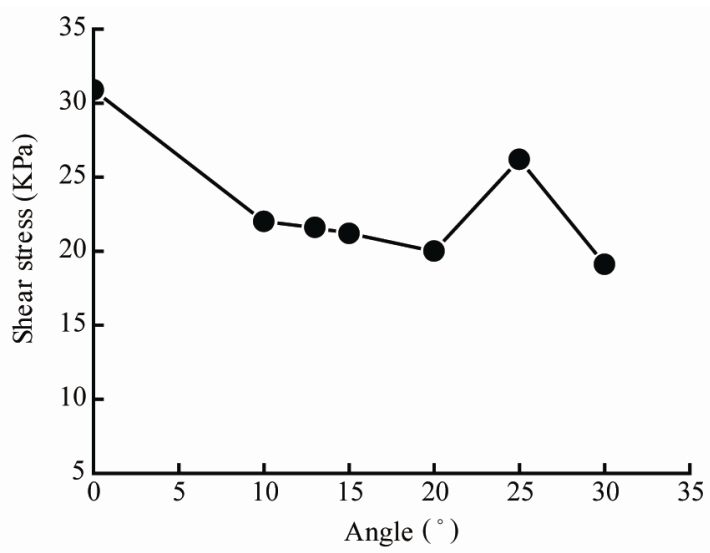

Figure 10. Maximum shear stress vs ejection angle.

Figure 9 that with the increasing of ejection angle, maximum water pressure is increased at first and then decreased while ejection angle $\theta$ is $0^{\circ}-20^{\circ}$, which shows that there is a optimal ejection angle to generate maximum water pressure. And the optimal ejection angle is about $13^{\circ}$ as shown in Figure 9. It can be seen from Figure 10 that with the increasing of ejection angle, maximum shear stress is decreased. When ejection angle is very small, maximum shear stress is big. When ejection angle is $10^{\circ}-20^{\circ}$, maximum shear stress is almost the same. It can be seen from Figure $\mathbf{1 1}$ that with the increasing of ejection angle, maximum hitting power is decreased sharply. 
Table 1. Cutting hole depth measurements vs working pressure.

\begin{tabular}{|c|c|c|c|c|c|c|}
\hline $\begin{array}{l}\text { Working pressure } \\
(\mathrm{MPa})\end{array}$ & $\begin{array}{l}\text { \#1 hole depth } \\
(\mathrm{mm})\end{array}$ & $\begin{array}{l}\text { \#2 hole depth } \\
\text { (mm) }\end{array}$ & $\begin{array}{l}\text { \#3 hole depth } \\
\text { (mm) }\end{array}$ & $\begin{array}{l}\text { \#4 hole depth } \\
\text { (mm) }\end{array}$ & $\begin{array}{l}\text { \#5 hole depth } \\
\text { (mm) }\end{array}$ & Average hole depth (mm) \\
\hline 3 & 0 & 0 & 0 & 0 & 0 & 0 \\
\hline 5 & 0 & 0 & 1 & 1 & 2 & 1 \\
\hline 7 & 3 & 4 & 4 & 5 & 4 & 4 \\
\hline 9 & 16 & 12 & 13 & 14 & 15 & 14 \\
\hline 11 & 20 & 20 & 20 & 20 & 20 & 20 \\
\hline 15 & 20 & 20 & 20 & 20 & 20 & 20 \\
\hline
\end{tabular}

Table 2. Cutting hole depth measurements vs ejection range.

Ejection range (mm) \#1 hole depth (mm) \#2 hole depth (mm) \#3 hole depth (mm) \#4 hole depth (mm) \#5 hole depth (mm) Average hole depth

\begin{tabular}{cccccc} 
& 20 & 20 & 20 \\
$(\mathrm{~mm})$ & 12 & 12 & 2 \\
10 & 20 & 20 & 11 & 2 & 4 \\
15 & 6 & 6 & 2 & 1 & 0 \\
20 & 0 & 0 & 0 & 0 & 0 \\
\hline
\end{tabular}

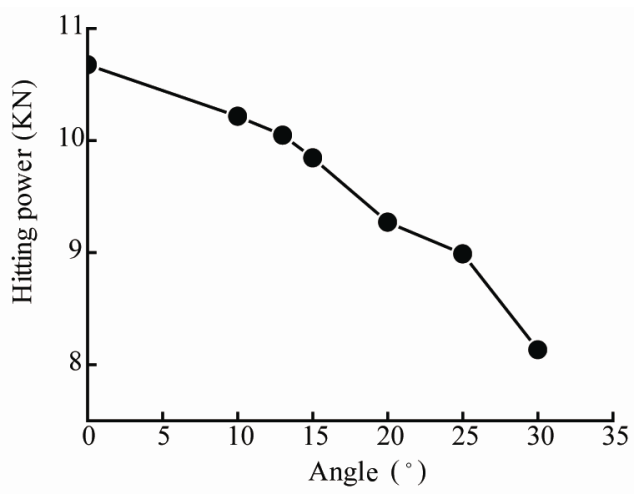

Figure 11. Maximum hitting power vs ejection angle.

Simulation results show that ejection angle is a key parameter to water jet cutting ability, but it is smaller than ejection range. There is an optimal ejection angle to ensure water jet with better comprehensive cutting ability. The optimal ejection angle is about $13^{\circ}$.

The simulation results are as follows: working pressure, ejection range and ejection angle of water jet system are main parameters to its cutting ability. Its important degree is in turn the working pressure, ejection range and ejection angle. To increase water jet system working pressure is the most effective way to improve its cutting ability. When working pressure is constant, ejection range should be less than $4 \mathrm{~mm}$ (four times of nozzle diameter) and ejection angle should be about $13^{\circ}$ so as to obtain best cutting ability.

\section{Experimental Tests}

Water jet cutting cobalt crusts tests were carried out to validate simulation results. It is difficult to obtain deepsea cobalt crusts sample. So cobalt crusts simulation material is used to replace deep-sea cobalt crusts. Cobalt crusts simulation material is composed of sand, lime and gypsum with a certain proportion [8]. Cobalt crusts simulation material performance parameters are as follows: thickness is $20 \mathrm{~mm}$, compressive strength is $2 \mathrm{MPa}-4$ $\mathrm{MPa}$, tensile strength is $0.1 \mathrm{MPa}-0.2 \mathrm{MPa}$. Nozzle diameter is $1 \mathrm{~mm}$. Water jet cutting ability is measured by measuring the depth of cutting hole.

Experiments of water jet working pressure and its cutting ability were carried out at first. The experiment conditions are as follows: working pressure is $3 \mathrm{MPa}, 5 \mathrm{MPa}$, $7 \mathrm{MPa}, 9 \mathrm{MPa}, 11 \mathrm{MPa}$ and $15 \mathrm{MPa}$ respectively. Under each pressure rating, water jet cutting experiment is repeated by 5 times. The average value of hole depth is consider as cutting depth under this pressure rating.

Table 1 is water jet cutting cobalt crusts simulation material experimental measurements under different working pressure. It can be seen from Table 1 that water jet can't cut cobalt crusts simulation material when water pressure is $3 \mathrm{MPa}$. There is a threshold pressure $5 \mathrm{MPa}$ during water jet cutting cobalt crusts simulation material. When water jet working pressure is less than $5 \mathrm{MPa}$, water jet can't cut cobalt crusts simulation materials. When water jet pressure is greater than $5 \mathrm{MPa}$, with the increasing of water jet pressure, water jet cutting ability is increased quickly.

Experiments of water jet ejection range and its cutting ability were carried out at second. The experiment conditions are as follows: working pressure is $11 \mathrm{MPa}$, ejection range is $5 \mathrm{~mm}, 10 \mathrm{~mm}, 15 \mathrm{~mm}$ and $20 \mathrm{~mm}$ respectively. Under each ejection range, water jet cutting experiment is repeated by 5 times. The average value of hole depth is consider as cutting depth under this pressure rating.

Table 2 is water jet cutting cobalt crusts simulation material experimental measurements under different ejection range. It can be seen from Table 2 that water jet can breakdown cobalt crusts simulation material when ejection range is $5 \mathrm{~mm}$. When ejection range is $10 \mathrm{~mm}$, 
Table 3. Cutting hole diameter measurements under different ejection angle.

\begin{tabular}{|c|c|c|c|c|c|c|}
\hline Ejection angle $\left({ }^{\circ}\right)$ & $\begin{array}{l}\# 1 \text { hole diameter } \\
(\mathrm{mm})\end{array}$ & $\begin{array}{l}\text { \#2 hole diameter } \\
(\mathrm{mm})\end{array}$ & $\begin{array}{l}\text { \#3 hole diameter } \\
(\mathrm{mm})\end{array}$ & $\begin{array}{l}\text { \#4 hole diameter } \\
(\mathrm{mm})\end{array}$ & $\begin{array}{c}\text { \#5 hole diameter } \\
(\mathrm{mm})\end{array}$ & $\begin{array}{l}\text { Average hole diameter } \\
(\mathrm{mm})\end{array}$ \\
\hline 0 & 3 & 2 & 3 & 4 & 3 & 3 \\
\hline 13 & 5 & 5 & 6 & 5 & 5 & 5 \\
\hline 30 & 3 & 2 & 4 & 3 & 3 & 3 \\
\hline
\end{tabular}

water jet can cut shallow hole on cobalt crusts simulation material surface. With the increasing of ejection range, water jet cutting ability is decreased quickly. When ejection range is $20 \mathrm{~mm}$, water jet can't cut cobalt crusts simulation material.

At last, experiments on water jet ejection angle and its cutting ability were carried out. The experiment conditions are as follows: working pressure is $5 \mathrm{MPa}$, ejection range is $2 \mathrm{~mm}$, ejection angle is $0^{\circ}, 13^{\circ}$ and $30^{\circ}$ respecttively. Under each ejection angle, water jet cutting experiment is repeated by 5 times. The average value of hole diameter is consider as cutting diameter under this pressure rating.

Table $\mathbf{3}$ is water jet cutting cobalt crusts simulation material experimental measurements under different ejection angle. It can be seen from Table 3 that water jet cutting ability is best when ejection angle is $13^{\circ}$.

\section{Conclusions}

With simulation calculations and experimental tests, the relationship between water jet system parameters and its cutting ability are obtained.

Simulation results coincide with experimental results, which show that the simulation model is feasible.

Working pressure, ejection range and ejection angle of water jet system are three main parameters to its cutting ability. Its important degree is in turn the working pressure, ejection range and ejection angle. In real cutting system, the optimal ejection range is less than $4 \mathrm{~mm}$ and ejection angle is about $13^{\circ}$.

\section{Acknowledgements}

Project 50804054 supported by National Natural Science
Foundation of China.

\section{References}

[1] Y.-J. Shen, G. X. Zhon, Z.-Q. He, "Present Status of Investigation and Development of Ocean Cobalt Crust Resources," Mining and Metallurgical Engineering, Vol. 19, No. 2, 1999, pp. 11-13.

[2] Aoshika, Katsuyuki, Zaitsu, Masaru Lto, Hidenobu, et al., "Experimental Study of Cutting the Cobalt-Rich Manganese Crusts,” NKK Technical Review, Vol. 59, 1990, pp. 61-67.

[3] Y. Liu, "The Theoretical and Experimental Research of the Methoud for Appling Twist-Roller to Cut and Collect Deep-Sea Colbalt Crust,” Ph.D. Dissertation, Central South University, Changsha, 2001.

[4] B.-H. Yuan, "Experimental Research on Coblat Crust Vibration Cutting Law,” M.S. Dissertation, Central South University, Changsha, 2004.

[5] Z.-H. Huang, S.-J. Liu, Y. Xie, “Obstacle Performance of Cobalt-Enriching Crust Wheeled Mining Vehicle,” Journal of Central South University of Technology, Vol. 13, No. 2, 2006, pp. 180-183.

[6] Y.-J. Zhou, "Research on Water Jet Cutting Cobalt Crust,” M.S. Dissertation, Central South University, Changsha, 2010.

[7] G.-L. Yang, W.-H. Zhou, F. Liu, "Simulation of Flow Field of High-Pressure Water-Jet from Nozzle with Fluent," Journal of Lanzhou University of Technology, Vol. 34, No. 2, 2008, pp. 49-52.

[8] C.-J. Qiu, "The Study on the Characteristics of Cobalt crust and Substrate rock for Simulation,” Ph.D. Dissertation, Central South University, Changsha, 2002. 